\section{Commentary: Techniques of mitral valve repair: Is there still "gunpowder" to be invented?}

\author{
Manuel J. Antunes, MD, PhD, DSc
}

Mitral valve repair, especially for degenerative disease, is increasingly gaining the preference of the surgical community and is now given a Class I indication in the guidelines. Results are progressively better and the procedure more reproducible. After the original works by Carpentier and colleagues ${ }^{1}$ Duran and Ubago ${ }^{2}$ and others who, in the $70 \mathrm{~s}$ and 80s, defined the basic concepts and designed the techniques still in use today, in what became known as the French Correction, ${ }^{3}$ only relatively minor modifications were introduced, all based on the same principles defined initially. Exceptions to this are, conceivably, the Alfieri procedure, used by some surgeons in some cases, and the artificial chordae (polytetrafluoroethylene), pioneered by Frater and now accepted by the majority. Countless numbers of minor modifications have been described that may either be technical improvements or adjuncts to help in assuring the surgeon that the immediate end result is going to be adequate before the valve can reinitiate function, that is, after discontinuation of cardiopulmonary bypass.

The latter better defines the method described by Morisaki and colleagues, ${ }^{4}$ from Osaka, Japan, in this issue of the Journal. In their work, the authors made a retrospective review of 350 patients who underwent mitral valve repair with the loop technique via median sternotomy or right mini-thoracotomy, over a 10-year period. They used gentian violet "ink-dotted" lines between the rough and clear zones

\footnotetext{
From the Clinic of Cardiothoracic Surgery, Faculty of Medicine, University of Coimbra, Coimbra, Portugal.

Disclosures: The author reported no conflicts of interest.

The Journal policy requires editors and reviewers to disclose conflicts of interest and to decline handling or reviewing manuscripts for which they may have a conflict of interest. The editors and reviewers of this article have no conflicts of interest.

Received for publication May 11, 2020; revisions received May 11, 2020; accepted for publication May 21, 2020; available ahead of print June 1, 2020.

Address for reprints: Manuel J. Antunes, MD, PhD, DSc, Faculty of Medicine, University of Coimbra, 3000-075 Coimbra, Portugal (E-mail: mjantunes48@sapo.pt). JTCVS Techniques 2020;3:124-5

2666-2507

Copyright (C) 2020 The Authors. Published by Elsevier Inc. on behalf of The American Association for Thoracic Surgery. This is an open access article under the CC BY-NCND license (http://creativecommons.org/licenses/by-nc-nd/4.0/).

https://doi.org/10.1016/j.xjtc.2020.05.020
}

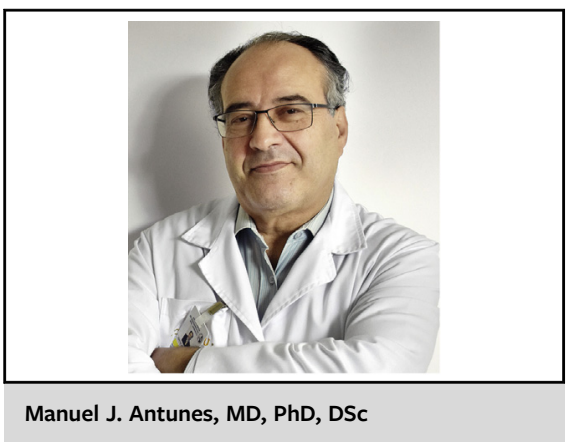

\section{CENTRAL MESSAGE \\ The lack of a control group does not allow us to fully understand how this new method has changed the results, hence; it does not help us understand if this is significant progress in mitral repair.}

of the anterior leaflet and in the center of the posterior leaflet, which they target to be the apposition line after completion of the repair. According to this marking, the surgeon adjusted the fixing position of the polytetrafluoroethylene loops. The authors claim good results with regards to survival and freedom from reoperation and from moderate to severe recurrent mitral regurgitation (MR) after 10 years of follow-up (only 5 patients at risk at this time; mean follow-up, approximately 5 years - not supplied). No significant differences were found in the rate of reoperation or recurrent MR between patients who did or did not require adjustment of the repair after the ink-dot marking test. The authors thus concluded, cautiously, that "this test may be a reliable technique for decreasing residual MR, especially when using the loop technique."

Every new technical adjunct to help in the repair is welcome and merits publication, and I congratulate the authors on that. However, the results of the repair in their study are similar to those reported up to now by a countless number of authors. In fact, I have seen better! It is worth noting that $20 \%$ of the patients developed late MR greater than moderate/severe. Furthermore, in this series, there was no difference in the need for a second pump run between those needing further adjustment on the technique and those who did not, which suggests that the technique described does not necessarily succeed in optimizing repair and may not be superior to the most 
commonly used ink line drawn during the water test after repair. Some of us don't even use ink; obviously, "there is more than one way to skin a cat!" I, therefore, have some doubts about the added value of this "adjunct." Also, because I am not particularly fond of the loop technique, the lot of natural chordae inserted along the free edge of the leaflets, especially the anterior leaflet, are not of the same length, hence the loop does not fit my concept of restoration of the anatomy as much as possible.

Naturally, each surgeon has his or her own tricks, but we have to be careful in not attempting to convince the others that a particular method is a new "discovery of the gunpowder." Besides, there are some limitations in this study. First, the population is very heterogeneous and not limited to degenerative disease, including different types of disease (anterior vs posterior vs bileaflet prolapse), and we know how the anatomy and physiology is different between etiologies. This may have had an impact in the degree of late recurrence of MR. Second, there was a wide variation in the way the neochords were implanted, and several types of ring annuloplasty were used. Also, the loop-in-loop technique, which was used in one quarter of the patients, came as an independent predictor for recurrence of MR. Finally, I had some difficulty in correlating the echocardiographic (transesophageal echocardiography) assessment of the valve after discontinuation of cardiopulmonary bypass, especially if we consider that some patients were allowed to leave the operation room with significant (more than moderate) residual MR. We all now recognize the fundamental role of transesophageal echocardiography during mitral valve repair procedures. It appears that, in this case, the surgeons had greater faith in their "technique" than in the echo results, despite the fact that $10 \%$ of the patients required a second pump-run to adjust the length of the artificial chordae.

Two early complications in this series are worrying and not completely explained. There were a number of cases of circumflex artery injury. I have previously drawn the attention to the fact that the incidence of this complication is probably greater than recognized, ${ }^{5}$ but the rate in this series exceeds what could be expected. On the other hand, the rate of left ventricular free wall rupture also seems high, and it is not clear in what type of patients/disease did this complication occur.

In conclusion, as one of the reviewers stated during the editorial process, "the lack of a control group does not allow us to fully understand how this new method has changed the results and, therefore, does not help us in understanding if this is a significant progress in mitral valve repair."

\section{References}

1. Carpentier A, Deloche A, Dauptain J, Soyer R, Blondeau P, Piwnica A, et al. A new reconstructive operation for correction of mitral and tricuspid insufficiency. J Thorac Cardiovasc Surg. 1971;61:1-13.

2. Duran CMG, Ubago JL. Clinical and hemodynamic performance of a totally flexible prosthetic ring for atrioventricular valve reconstruction. Ann Thorac Surg. 1976;22:458-63.

3. Carpentier A. Cardiac valve surgery-the "French correction". J Thorac Cardiovasc Surg. 1983;86:323-37.

4. Morisaki A, Takahashi Y, Fujii H, Sakon Y, Murakami T, Shibata T. Loop technique with ink-dot marking test: an alternative strategy to the ink test. J Thorac Cardiovasc Surg Tech. 2020;3:110-21.

5. Coutinho GF, Leite F, Antunes MJ. Circumflex artery injury during mitral valve repair: not well known, perhaps not so infrequent-lessons learned from a 6-case experience. J Thorac Cardiovasc Surg. 2017;154:1613-20. 